\title{
2 The circular economy in China
}

In the Chinese view, the concept of the circular economy is based on the three principles of Reduce, Reuse, and Recycle. The rapid growth and industrialization of China over the past 40 years or so has given rise to more and more detrimental environmental pollution, which compounds concerns about increasing waste and decreasing resources. The circular economy is meant to serve as a response to these environmental challenges and to reconcile economic and ecological imperatives by decoupling economic growth from natural resource depletion and environmental degradation $(\mathrm{Q} i$ et al., 2016; Murray, Skene, and Haynes, 2017). In their comparative research on the definitions of 'circular economy' that circulate in China and Europe, McDowall et al. (2017) have established that the Chinese plans focus more on the combatting of pollution, sustainable development, and ecological civilization, while Europe is more concerned about solutions for waste and the opportunities for industry these solutions may bring (Blomsma and Brennan, 2017). By striving to rebalance economic development while also accounting for social and environmental objectives, China is attempting to achieve a state of harmonious development (Naustdalslid, 2014). The combination of ecological civilization - defined as China's long-term vision of sustainable development - and the circular economy fits the political narrative of 2002, when both these concepts were first introduced (Geall, 2015a). More concretely, elements such as resource efficiency, green technologies, and waste management were paired with calls to build a resource-saving and environmentally friendly industry and society (McDowall et al., 2017). The policy of creating a harmonious society - including a harmonious approach to development - is very much associated with the Hu Jintao era (2002-2012), but Hu's successor Xi Jinping has also continued to support it (Naustdalslid, 2014; Marinelli, 2018). The policy of creating an ecological civilization was incorporated into the CCP Charter at the 18th National Party Congress in 2012 and has been considered a key element of China's national development strategy since then (Kuhn, 2016; Marinelli, 2018).

The idea of the circular economy was first brought up by scholars in 1998 (Yuan, Bi, and Moriguichi, 2006). The circular economy as a strategy was formally adopted as a policy starting in 2002, but it took time to formulate the concrete measures by which it would operate. Environmental regulatory regimes based on concepts of cleaner production, industrial ecology, and ecological modernization that were already in place in Germany (i.e., The Waste Avoidance and Management Act, 2002), Japan (i.e., The Basic Law for 
Establishing a Sound Material-cycle Society, 2002), and elsewhere, inspired the Chinese government to set up a number of pilot projects to explore how to implement the circular economy strategy (Someno, 2014; Blomsma and Brennan, 2017; Murray, Skene, and Haynes, 2017). After these tests, the Circular Economy Promotion Law (also known as the Recycling Economy Promotion Law) was adopted in 2009. It aimed to improve resource utilization efficiency, protect and improve the environment, and realize sustainable development (National People's Congress Standing Committee, 2008: art. 1; Liu, Zhang, and Bi, 2012; Naustdalslid, 2014). Environmentalists saw the law as concrete proof that all the talk about the necessity of establishing an ecological civilization through a circular economy was now being matched with deeds. In the years following the adoption of this general law, specific legislation was added to clarify where the rules were to be enforced, including the sectors of municipal waste, industrial waste, and wastewater (Qi et al., 2016: 41-44). While the plans and strategies were committed to the concepts of reducing, reusing, and recycling, they put less emphasis on measures that would influence patterns of consumption. Instead, specific manufacturing sectors and potential policies were scrutinized to increase efficiency and reduce waste and pollution in manufacturing (McDowall et al., 2017). To facilitate conversion to a circular economy, a Special Fund for Circular Economic Development was set up in 2012, but who can apply and which projects are funded remains unclear (Nelles et al., 2017). China's adoption of the circular economy has been a boost for the adoption of elements of the concept elsewhere (Murray, Skene, and Haynes, 2017: 369). Yet, the implementation of the circular economy is less developed than its theory and principles may suggest, and the process of transforming the economy to be more sustainable has not, in fact, made much headway (Yuan, Bi, and Moriguichi 2006; Naustdalslid, 2014: 308).

\section{Incineration as part of the circular economy}

Accompanying the adoption of the circular economy, incineration has been embraced as the ultimate solution for the waste problem. Indeed, incineration is said to effectively achieve more than a go percent reduction of waste volume (Y. Li et al., 2015: 234). However, as Martin Melosi has argued, incineration should not be seen as a potential disposal panacea: it is just one of several disposal options that are available, and what is needed is a determination of under what circumstances incineration serves which disposal needs best (Melosi, 1996: 41, 40). Incinerators not only deal with the 
waste itself, but more importantly, they can also produce and generate the amounts of energy (Waste to Energy, WtE) that are needed for continued economic development and growth while decreasing the burden on the environment. This makes incineration more attractive than other wastedisposal methods. The amount of power generated by incineration since the beginning of the 12th Five-Year-Plan has steadily increased: the amount for Shanghai rose from 24 to $5^{8}$ percent, for Beijing from 13 to 45 percent, and for Guangdong from 34 to 56 percent (Y. Li et al., 2015: 239). By generating electricity during waste disposal, the air pollution caused by (coal burning) power plants can be reduced considerably. This is an attractive alternative, as the blue skies push that has been underway for some time has resulted in the closing down of many of the smaller and older coal burning power plants still in operation around and in urban areas (Kennedy and Chen, 2018). China is one of, if not the largest global energy consumers and relies to a large extent on the importation of energy resources from abroad to satisfy demand (Albores, Petridis, and Dey, 2016). Since the supply of energy resources from abroad is influenced by political stability elsewhere, as well as global pricing policies, the domestic production of energy resources creates a certain level of self-sufficiency. The Chinese domestic energy demand has shown a steady increase over the past decades, and there are no indications that it is slowing down.

In the process of burning the waste, however, the desired closed loop of the circular economy is broken because any potentially reusable resources left in the waste are evaporated. This calls for a pre-sorting stage prior to incineration, which however negates the idea that all waste can simply be chucked into the incinerator and be done with. This pre-sorting or recycling stage is where 'Internet Plus Recycle' companies with $\mathrm{O}_{2} \mathrm{O}$-business models, discussed in more detail below, develop their activities. Better sorting and recycling practices of the general residents would also improve incineration effectiveness (Wan, Chen, and Craig, 2015).

The number of incineration plants nationwide has nearly doubled, from 238 in 2010 to 514 in 2015 (Yuan and Li, 2017), but due to the fast rate of expansion a credible and up-to-date inventory of all of the MSW incinerator plants is lacking (J.-W. Lu et al., 2017). Given the urgency of the waste problem, the disposal of garbage through incineration is seen as one of the pillar industries in the current 13th Five Year Plan (2015-2020); as a result, tens of billions of yuan are being poured into the construction of an infrastructure of incinerator plants all over the country (Compilation and Translation Bureau, 2016; Goldstein, 2016). This should double China's incineration capacity by 2020 (Yuan and Li, 2017). The central government 
uses the promise of state funding for incineration plants as an incentive to prod local governments into improving their environmental performance (Heberer and Senz, 2011). Densely populated large cities with scarce land resources see WtE incinerators as the most desirable waste processing technology because of its high efficiency, minimal land requirement, and significant impact on the reduction of solid mass. Incineration technology is seen by some as the only alternative to landfills (Wan, Chen, and Craig, 2015).

The demand for incinerator facilities has created a frenzied buyers' market for companies developing the technology and equipment. As early as 2009, research indicated that over one-half of the global orders for new waste incineration factories came from China (Balkan, 2012). The companies try to outbid each other with exceptional offers and claims of performance. Allegedly, bribes are also offered to the officials who are responsible for acquisition. These rumoured acts have come under threat as a result of the anti-corruption campaign that started in 2014-2015, which has brought down many corrupt officials at all levels. To undercut the competition, Chinese companies are said to offer unbelievably low burn rates. This suggests that the required air-pollution control systems, such as flue-gas filtering, are not installed, or that other cost-cutting methods have been employed (Balkan, 2012; J.-W. Lu et al., 2017). In 2018, the newly reorganized Ministry of Ecology and Environment once more addressed this pressing issue of flaunting emission standards, with the promulgation of the 'Action Plan for Straightening out the Municipal Solid Waste Incineration Power Generators to Meet Emission Standards' (MEE, 2018).

\section{Implementation of laws and regulations and their constraints}

In April 2015, the Party Central Committee promulgated Central Document Number 12: 'Opinions of the Central Committee of the Communist Party of China and the State Council on Further Promoting the Development of Ecological Civilization' (Central Committee, 2015). The document signalled a break with the past in that it announced a shift in policy priorities from economic growth to sustainable development. Although classified as mere 'Opinions', this document did not voice high-level intentions but instead proposed actual standards, mechanisms, and assessments to improve policy implementation (Kuhn, 2016; Geall, 2015a, 2015b, 2015c). These 'Opinions' defined the circular economy in terms of reusing and recycling resources, as opposed to simply extracting them, using them for manufacturing, and then consigning them to waste. The policy document further illustrated the 
government's commitment to the policy and assured that the 'Opinions' would have a major influence on the formulation of the 13th Five Year Plan for the period 2015-2020 (Geall, 2015b). The 'Opinions' reflect Xi Jinping's ambition to reroute the course of economic development towards a more environmentally friendly direction. This is illustrated by the inclusion of the lines 'the great value of lucid waters and lush mountains'. Xi first uttered these in 2005 while serving as a CCP chief in Zhejiang Province (Geall, 2015a; Zhejiang Provincial Committee 2016). Xi's remarks, now known as the 'Two Mountains Theory' of 'clear waters and lush mountains are invaluable assets that are comparable to gold and silver', have since become an important principle for discussing Chinese development (Ministry of Foreign Affairs, 2016). The document signalled to the rest of the administrative and political structures that the highest levels of both Party and State administration were serious about bringing ecological improvements and that the lower authorities needed to shape up (Liu et al., 2015).

Ran Ran (2013) has argued that China's environmental governance shows a paradox. While there is great awareness of environmental problems at the central levels of government and a comprehensive and modern set of environmental legislation has been promulgated to pursue sustainable development and environmental progress, none of this seems to have produced noticeable structural effects in practice. This state of affairs stems from the assumption held by the Chinese authorities that once they have at their disposal the correct factual knowledge about the state of affairs in society, adequate measures and policies will follow and implementation will be assured (Naustdalslid, 2014: 309, 310). To put it more strongly, in the words of a Chinese legal scholar, China's green laws are useless, as they are symbolic (as quoted in Simões, 2016).

The compliance and implementation of government decisions are obstructed by a number of interrelated causes, with China's extremely decentralized governing structure the root problem. Central government initiatives and laws tend to be 'showcase politics': ambiguous, inexplicit, unclear, vague, and overly reliant on good intentions rather than on hard measures, goals, and timetables that can be measured. Such policy expressions are intended to focus the attention of the bureaucracy on a particular policy area, and the mobilization of the commitments and focus of the bureaucracy itself is the most important target, rather than the implementation of the policies (Strauss, 2006: 896; Kennedy and Chen, 2018). This is particularly visible when it comes to environmental rules and regulations (Ran, 2013).

The relative lack of success of the implementation of environmental legislation is further illustrated by the ineffectiveness, caused by its low status 
and weak bureaucratic influence, of the institution that was responsible for environmental affairs. The former State Environmental Protection Bureau, which was responsible for all of the environment, used to be a mere bureau under the authority of the Ministry of Urban and Rural Construction. In 1988, it became a vice-ministerial level department and in 1998 it was upgraded to become the State Environmental Protection Administration, situated directly under the State Council but not a component of it. As a result of its low bureaucratic level, it was unable to press its case in confrontations with stronger, economically more important ministries. It was only after its elevation to full ministerial status in 2007 that the Ministry of Environmental Protection (MEP) gained importance and bureaucratic clout (Heberer and Senz, 2011; Qi et al., 2016). In 2018, the MEP was reorganized and renamed the Ministry of Ecology and Environment (MEE), which concentrated the various lower-level bureaucracies active in the fields of ecology and environment into one centralized structure (MEE, 2018). As concerns about the environment have increased, so has the power of the organization, in the process taking over responsibilities that were previously overseen by the National Development and Reform Commission (Kostka and Zhang, 2018).

The fact that China is a diverse country with widely different local characteristics and levels of prosperity has created a tendency for the central government to formulate standards rather than give explicit policy directives. In other words, the government more or less sets the agenda and leaves it to the local levels to bargain and modify the central policies into concrete measures (Heberer and Senz, 2011). As a result of decentralization, the Centre has retained only weak control over policy implementation and, as many scholars have pointed out (Ran, 2013; Heberer and Senz, 2011; Kostka, 2014; Kostka and Mol, 2013; Lo, 2015), there are few incentives for local officials to actually take sides when conflicts of interest arise between national regulations and local stakeholders. Moreover, the central authorities are prone to adopt symbolic legislation and displays of exemplary behaviour without first assessing whether their policies can be implemented. One example is the Circular Economy Promotion Law mentioned above, a policy document that sets out principles but at the same time lacks concrete standards and mechanisms. The officials who are responsible for its implementation do not understand its procedures and aims, and there is no broad popular support for the principle of the circular economy because the general public is hardly aware of it (Naustdalslid, 2014: 310, 311).

The Chinese ratification of the Paris Agreement on 3 September 2016, part of the United Nations Framework Convention on Climate Change, which was adopted on 12 December 2015, is another example of this symbolic posturing 
(Kuhn, 2016). ${ }^{2}$ On the basis of its past opposition to global environmental initiatives and as one of the major contributors to climate change, the Chinese government's support for the Agreement came as a surprise. The country was globally praised for its clear-sightedness, gaining considerable symbolic capital in the process. Many, mainly foreign, observers had to reconsider their often-outspoken critical position towards China when it comes to the environment. The praise only grew in intensity once the United States announced its withdrawal from the Agreement in 2017 and China was expected to take over as the global climate change leader (Kostka and Zhang, 2018). However, the real burden of implementing the conditions of the Agreement was shifted onto the shoulders of the lower and local bureaucratic levels, which have to come up with ways to make the changes that will enable China to comply with the goals it has underwritten.

\section{Performance Evaluation}

Usually, Chinese government officials at all levels occupy their positions for a period of five years, although a 3.5-4 year period is also frequently encountered (Kostka, 2014). It is every bureaucrat's aim to be promoted to a higher, or better, position. Occupational improvement can take the form of higher rank; additional wages or bonus payments; a better working environment (i.e., promotion to a bigger city, a bigger department, etc.); more access to allowances like subsidized housing; and so on (Kostka, 2014). To be eligible for promotion, every official has to submit to the so-called Cadres Performance Evaluation System, which is run by the Organization Department of the Party. This system specifies sets of targets that local cadres must fulfil. In very general terms, the targets include morality, capability, diligence, performance, and probity, but most are very concrete (Ran, 2013). The Organization Department can add targets and mark them as either 'hard' or 'soft'. Hard targets include GDP growth, maintaining social stability, successfully upholding the One Child Policy (until 2016), etc. Most of these hard targets additionally have 'veto power': if one of them is not accomplished, all other targets, even when successfully met, are annulled (Heberer and Senz, 2011; Kostka, 2014). Economic development was and still is seen as most important, while environmental measures were often seen as problematizing or impeding growth; environmental targets were 'soft' and tended to have fairly low priority in the evaluation rankings. A 
complicating factor in the enforcement of environmental measures is that measurements of the outcomes and effects of some hard target policies, like GDP growth, are easier to establish than those of soft target policies. It is relatively easy to prove that no demonstrations or riots have occurred in one's jurisdiction, or that the birth-rate has declined. The results of a greening policy, on the other hand, may take years to become visible. The push in recent years to increase the number of 'blue days', days when air pollution is successfully reduced, in major cities, results in numbers that cannot be disputed (Kennedy and Chen, 2018). However, the effects of policies that need a longer time to come to fruition will not be recorded on the score sheet of the officials who have enforced them, and their successors will reap the benefits instead. Understandably, officials are wary of working to improve the reputation of others and this generally impedes the implementation of environmental policies (Kostka, 2014; Eaton and Kostka, 2014).

Moreover, the decentralized nature of the political system means that the institutions that are tasked with implementing policies suffer from overlapping or contradictory responsibilities while also facing strong boundaries between administrative entities. Local Environmental Protection Bureaus (EPBs), for example, are responsible for supervising and enforcing the environmental regulations handed down from the higher levels, but they are dependent on other sections of the local government for their financial resources and staff (Liu, Zhang, and Bi, 2012; Heberer and Senz, 2011). It is clear that EPBs can be forced to temporize or simply refrain from enforcing policies when other sections of the administrative structure consider them detrimental to realizing their own goals. Development and Reform Commissions at the local levels are formally responsible for master planning for ecological improvement and environmental protection, but their top priorities are effectively industry development and investment in public infrastructure developments. Land Resource Bureaus are formally responsible for land, mineral, and marine resource protection, but they see collecting land and mineral resource fees as their main priority (Ran, 2013; Kostka, 2014). These bureaucratic impediments make it extremely difficult to enforce environmental policies that run counter to the development agenda that drives the locality. However, since the adoption of the 11th Five Year Plan in 2006, a number of environmental targets have been upgraded to 'hard' status level. This should ensure that these targets are implemented (see Lo, 2015: 154, 155 for the specific targets). Added to this is the growing conviction, also mentioned in Central Document Number 12 ('Opinions'), that an official's non-compliance with state-set environmental targets should be permanently included in his/her personnel file, thus influencing 
his/her future career chances (Geall, 2015a, 2015c; Zhang, 2015; Kuhn, 2016). Note that the 'Opinions' merely express a conviction; no concrete steps have yet been taken.

Despite these changes, complying with central government policy orders that are identified as hard targets is often at loggerheads with local demands, situations, and peculiarities. There are many occasions where it is more prudent to accommodate these local needs rather than implement central policy. In the worst cases, policies are only implemented selectively, or formally, without any concrete actions undertaken (Heberer and Senz, 2011; Kostka, 2014; Lo, 2015; Interview with Hong Chao, 2017).

\section{Compliance with laws and regulations and its constraints}

The decentralized administrative system currently in place in China lacks the means of enforcing the strict implementation of environmental policies and laws and has no tools for deterring lower levels of government from breaking the rules. How can compliance be enforced? This question is not only relevant for the behaviour of different layers of bureaucracy and the individuals manning them: it also has implications, as we shall see in later chapters, for all of society, down to the level of individual residents of urban residential communities. Individual behaviours regarding garbage classification and separation need to change to bring about the central government's goal of creating an ecological civilization. To put the question differently: if and when there are rules and regulations, why are they not implemented and internalized by officials and civilians alike?

As Benjamin van Rooij and others have shown, the study of compliance in China has only recently been taken up. Although the topic has been researched exhaustively in Western contexts, it is too early to tell whether the results of these studies can also apply elsewhere (Yan, van Rooij, and van der Heijden, 2016; Van Rooij et al., 2017). The extensive research on compliance in various instances of ecological legislation and related topics that Van Rooij and his collaborators have undertaken in recent years has unearthed some interesting findings that are pertinent to the question of individual compliance. The reasons for bureaucratic inertia are not difficult to find. More interesting is the lack of compliance with rules, regulations, programmes, and projects on the part of urban residents - the people who should be on the receiving end of policies, which apparently have not been handed down well from the centre to the locality. The preceding discussion has illustrated how a lack of enforcement or deterrence for non-compliance 
has allowed the responsible administrative layers to disregard promptings from higher levels in the bureaucracy; in practice, the same process applies to the residents. Despite intensive propaganda and other activities designed to influence and change their attitudes, residents seem unwilling and/or unable to internalize behaviour that is beneficial for improving the environment.

The previously mentioned compliance researchers Yan, van Rooij, and van der Heijden have established that, apart from forcing compliance through enforcement and deterrence measures, the factor of voluntary compliance is crucial for determining behaviours. Voluntary compliance is influenced by three conditions. The first concerns the operational costs and benefits of compliance and violation beyond punishment. None of the environmental plans and pilot projects organized until now mention a threat of punishment or provide opportunities to shame shirkers at the lowest levels for not acting in accordance with legislation. The second condition refers to the legitimacy of compliant behaviour. Legitimacy can be broken into four constituent factors: social norms, personal morals, perceived sense of duty, and procedural justice. Social norms are what educational campaigns attempt to instil: when others are engaging in this sort of behaviour, I will comply, as it is probably right. Personal morals touch upon whether one personally considers an action to be morally right. A perceived sense of duty comes from the feeling that one has to act in a certain way because it is seen as a general duty. The last factor, procedural justice, is related to whether one perceives the suggested behaviour as fair. The final condition is the capacity to obey the law. Again, present policies lack any pressure to obey any law on the level of the individual (Yan, van Rooij, and van der Heijden, 2016: 211-212).

The decision of an administrative level to not comply with rules and regulations handed down from higher levels is not influenced by aspects of voluntary compliance. The organizational unit is constrained on all sides to behave and follow the other units. When it comes to the individualized behaviour of urbanites, it is clear that much more is needed to bring about voluntary compliance than merely publishing laws and regulations or putting up posters, no matter which administrative level is doing so. Implementation of a third-party surveillance mechanism would be a first step. Recently, a system of rewards and punishments has been announced through the Social Credit System that will be implemented in coming years (Chen, Geng, and Fujita, 2009; State Council, 2014). However, the difficulty to make individuals comply also points to the urgent need for more and different types of education and persuasion, almost to the level of the individual urban resident. Most citizens currently have no idea what is expected of them. The 
ongoing efforts to educate and persuade residents to start classifying and recycling their waste are taken up more extensively in Chapter 5 .

\section{Internet Plus}

Premier Li Keqiang proposed the 'Internet Plus' initiative in 2015 (State Council, 2015b). This was intended to add impetus to the creation of the circular economy and at the same time create a new engine for economic growth. The Internet Plus plan was adopted to 'integrate the mobile Internet, cloud computing, big data, and the Internet of Things with modern manufacturing, to encourage the healthy development of e-commerce, industrial networks, and Internet banking, and to guide Internet-based companies to increase their presence in the international market' (State Council, 2015b). On the one hand, the initiative was meant to facilitate the emergence of new, Silicon Valley-type high-tech industries and entrepreneurs. Another aim was to help older industries turn to the Internet to find new relevance and possibly stop them from folding altogether. The direction set out in the Internet Plus plan was further supported by one of the decisions at the 2016 Central Economic Work Conference, which stated that it was 'imperative to adopt and implement the new development concept, namely the concept of innovative, coordinated, green, open and shared development' (Wu, 2016).

Li Keqiang's Internet Plus initiative signalled to both the administrative levels and commercial sectors, particularly producers of information and communications technology (ICT), that the telecommunications network should be made more comprehensive and faster nationwide, allowing more people and more companies to become active online. Specifically, the relevant ministries and administrations were tasked with further establishing an internet infrastructure and formulating a 'Broadband China Plan' (Hou, 2015; Davidson, 2015; Fung Business Intelligence Centre, 2016). The better, cheaper, and faster telecommunications coverage that was promised benefitted the indigenous smartphone producers. Formerly known as shanzhai ('copy-cat') producers, they were now stimulated to come up with models that performed better than the much more expensive foreign brands, thus persuading more people to use them (Yang, 2016). By increasing the use of smartphones, more specially tailored applications could be developed to help stimulate another development strategy, the Made in China 2025 plan (State Council, 2015c). This plan envisions how China in 2025 will become technologically self-sufficient and turn into a manufacturing superpower by transitioning away from labour-intensive industries and toward advanced 
industries like robotics, advanced information technology, aviation, and new energy vehicles (Wübbeke et al., 2016; Laskai, 2018).

Many smaller entrepreneurs have come up with innovative initiatives under the wings of these programmes. Some of the outcomes of the strategy that are regularly praised by the Chinese media are initiatives to boost the rural economy. For example, the setting up of e-commerce production villages in the countryside is regularly featured in media reports and mentioned positively as a success. These villages have created employment and marketing opportunities, producing goods and selling products through online retail platforms like the one developed by the technology and retail giant Alibaba (Davidson, 2015). Looking at the situation in 2017 Beijing, the so-called $\mathrm{O}_{2} \mathrm{O}$ phenomenon (referring to online-to-offline activities, 线上 线下) has given birth to a wide range of business models and approaches to solve all sorts of social and consumer problems. Many if not most acquisitions in shops, most restaurant cheques, and most supermarket bills can now be paid through one's smartphone, by using one of the many online payment systems (wallet apps) that have been developed by companies such as Alibaba (i.e., AliPay). Ordering a taxi through a smartphone app, comparable to the way the Uber Company is operating in Western countries, was very much the thing to do around 2015 but seems to have fallen out of favour again.

\section{The sharing economy}

The most visible manifestation of Internet Plus has been the growth of the sharing economy, which gives substance to the reduction of consumption and waste generation as envisioned in circular economy philosophy. Numerous companies (OfO, MoBike, BlueGogo, etc.) started to operate dockless bicycle-sharing services in 2016, putting brightly coloured bicycles in the street that can be unlocked for use by scanning a QR-code attached to their seats or frames and making payment through one's smartphone (Lan et al., 2017). ${ }^{3}$ This has proven a huge success: in 2017, MoBike was awarded the first China Social Enterprise Award for its innovative business model and approach to solving social problems; the Awards are organized by the Social Investment Forum and China Social Enterprise (Bhandari, 2017; Carlson, 2017). The easy availability of bikes has brought about a true cycling craze in many urban areas. Renting a bike has put a curb on the use of automobiles; it has offered a solution for urban congestion as well as air pollution; and has 
even contributed to the fight against urban China's expanding waistlines by making people exercise more. By tracking each unlocked bike for the duration of its use through Internet of Things (IoT) technology, huge amounts of data are generated every second that can be used for urban planning purposes, such as establishing where gaps exist in public transit (Yin and Tan, 2017). Bike renting has come to account for a third major form of public transport (Yin and Tan, 2017; Fieldnotes 2017).

A negative side effect of this sharing craze is that the huge numbers of yellow (OfO), orange (MoBike), blue (BlueGogo), and other-hued bikes that are left behind on streets and street corners have created a major problem for urban management. They have made negotiating pedestrian routes and sidewalks practically impossible, particularly for those who are physically or visually impaired (Bhandari, 2017; Yin and Tan, 2017; Fieldnotes, 2017). Many urbanites criticize others for carelessly disposing of the bikes, grumbling about their users' lack of quality, i.e., just leaving their bikes wherever they please rather than parking them correctly in designated areas; moreover, they are not pleased about the waste created by wrecked and otherwise broken bicycles that are left behind to rust (Interviews, 2017; Taylor, 2018). The infatuation with the sharing economy has not stopped at bicycles or Uber-like taxis. Adventurous entrepreneurs have succeeded in persuading venture capitalists to finance plans for companies that offer umbrellas to share, or even shared smartphone battery packs (Chen, 2017; Lu H., 2017). As a result of this massive turn towards smartphone use for calling services, particularly in metropolitan areas, people's lives have become intimately, almost literally, linked to their phones; their eyes are glued to their tiny screens, not looking up. This has given rise to the moniker ditou zu ('bent-headed tribe'). While some argue that this phenomenon is largely concentrated among the so-called post-1980s and -199os generation of youngsters (baling hou, jiuling hou, the Chinese designation for millennials), one does not need to look very hard to see that older people have also become heavy smartphone users (Fieldnotes, 2015, 2017; Interviews, 2017).

While the Internet Plus plan clearly serves as a national agenda for development, it also leads to ever more moments and opportunities for the consumption of services and goods. The mushrooming services sector that runs on a $24 / 7$ schedule has become one of the new domains where surplus labour is absorbed, usually in the form of delivery persons or couriers; large quantities of migrants supply this surplus labour. It is also provided by the new urban underclasses that have been emerging, which consist of laid-off employees of former state-owned enterprises, or graduates from vocational schools or even universities who have been unable to find more 
fitting employment (Engebretsen, 2013; Evans, 2014; Liu, 2016). One of the greatest ironies of developing China may well be that while the population across the board has been able to go to schools and universities in larger numbers than ever before (Murphy, 2004), has become better educated than ever before, the supply of jobs for these educated and/or trained newcomers has not increased at the same speed.

It is hard not to notice the army of delivery persons who have become an indispensable part of the service sector. They are usually men, very occasionally women, and predominantly young, although one also encounters elderly delivery persons. They are often dressed in eye-catching work outfits and many make use of $\mathrm{O}_{2} \mathrm{O}$ bicycles to make better speed on the congested roads to deliver their orders. Food-delivery companies have been teaming up with $\mathrm{O}_{2} \mathrm{O}$ bike companies. Street corners are occupied by tricycle vanlets, operated by delivery men and women who pile their parcels on the street, waiting for customers who have ordered goods online, from their homes, their workplaces, or other places, to come pick them up. Car owners have their cars washed and waxed by mobile car-wash-and-wax teams, which use tricycle vanlets or small delivery vans to carry the equipment and liquids needed for the cleaning (Norcliffe, 2011). The number of couriers delivering take-out orders to the hungry defies counting. With China's ever-expanding economy, the possibilities and opportunities for the service industry seem endless, but in the end, it all comes down to more consumption; to spending more money; to individuals rendering services for others higher up on the economic ladder; and to producing more garbage and waste that needs to be dealt with. Parcels are wrapped in extravagant amounts of wrapping and packing tape; all food deliveries come packed in plastic or styrofoam.

\section{Internet Plus Recycle}

In the newly created niche of 'Internet Plus Ecology', institutions and companies have been invited to enhance the dynamic monitoring of resources and the environment, develop intelligent environmental protection, develop and complete the system of collecting and reusing waste and used resources, and build an online waste-trading system (State Council, 2015b). Using the term 'Internet Plus Recycle', a number of garbage disposal and recycling companies have become active in recent years that combine online and offline activities, hence their inclusion as $\mathrm{O}_{2} \mathrm{O}$-companies. They attempt to fill the gap left by the disappearance of the formal recycling structure, collecting recyclables and transporting them further upstream and competing with the 
informal waste collectors. Some of these companies are involved in the actual recycling process itself (Goldstein, 2006; Guo, 2016; Zhang, 2016). With the help of Chinese venture capitalist investors, many of these companies have developed smartphone applications to reach the citizens of Beijing and other urban areas (NDRC, 2016). Through these apps, they create dedicated user networks for their services, which include the collection of recyclables at the residents' doorsteps. Among these companies are Beijing Incom Resources Recovery Company (active in Beijing); GEM (Tianjin, Shenzhen, Wuhan); Zaishenghuo (Beijing); Beijing Zailai Keji (Beijing); and Baidu Recycle 2:0 (Beijing/Tianjin). As the last initiative focuses exclusively on the recycling of e-waste and smartphones, I have excluded it from this analysis.

The apps these companies have developed all look different, but they share some characteristics. They link waste producers with waste collectors or waste collecting systems. These apps show the user what his/her garbage is worth at any time: plastic and PET bottles are calculated per item, paper and cardboard by weight. The system of set prices means that haggling is no longer necessary. This may be beneficial for the person offering the recyclables, but not necessarily for the junk collector. The value of large objects like TV sets or washing machines usually has to be negotiated with the person picking them up, but not all companies adhere to that policy and have set prices. After indicating that scrap can be picked up, a waste collector, sometimes formally employed by the company behind the app, contacts the person offering the scrap; makes an appointment for the pick-up; and transfers the amount of money due through the options offered by mobile technology in the form of a wallet app (Zheng J., 2017). In the whole procedure, no cash money changes hands, further blocking opportunities for bargaining and embezzlement. Some companies that operate in a similar fashion do not transfer money at all, but have set up a system for saving points for consumer goods. On the basis of the number of points collected, one can order products that are then delivered by the same people who retrieve the recyclables. Some have argued that this merger of scavenging and mobile technologies results in the Uberization ${ }^{4}$ of an occupation that for decades has been the lifeline for millions of people moving from the countryside into urban areas (Pasquier, 2015). In the section of the smartphone application that contains the personal details of the user (telephone number, address, etc.), the total amounts of goods that have been recycled are stored. This

4 Uberization: 'Changing the market for a service by introducing a different way of buying or using it, especially using mobile technology', Cambridge Dictionary (https://dictionary. cambridge.org/dictionary/english/uberize), accessed 3 January 2017. 
big data can be used in Internet of Things-schemes, for example providing information to municipal sanitation departments for the improvement of garbage collection routines - but it can also be integrated at some point into the Social Credit System that the government wants to implement.

GEM, a company based in Wuhan with branches in Tianjin and Shenzhen, was one of the pioneers in the development of smartphone applications. In June 2014, GEM launched an app called Huishouge (Recycle Brother) in the presence of Yu Zhengsheng, member of the Chinese Communist Party Political Bureau and Chairman of the Chinese People's Political Consultative Conference (Guo, 2016). ${ }^{5}$ The support of such high-ranking officials serves as an indication of how in line these types of operations are with government policies. To perfect the operation of its app, GEM focused on the construction and improvement of online platforms, the layout of offline recycling systems, the construction of logistics and warehousing, the construction of R\&D teams and data centres, the promotion of online and offline advertising, and the exploration of environmental sanitation. Beyond that, the company has also invested in expanding its recycling network by building or integrating existing waste stations, setting up urban transit stations, and configuring logistics transportation between front-end recycling and transfer stations (Huishouge, 2017b). Since it runs services in Guangzhou, Shenzhen, and Wuhan GEM is involved in activities that are geographically more extensive and therefore covers more potential customers/users than the other companies that are concentrated in the metropolitan areas of Beijing or Shanghai, and yet it is not as well-known as the others (Zhang, 2016). In July 2016, GEM was recognized by the National Development and Reform Commission as a 'Top 100 Internet Plus' initiative on the basis of its unique business model and excellent recycling service (Huishouge, 2016).

Many other recycling companies have opted for a similar online-to-offline strategy. In 2016, an estimated 100 of them were registered (Zhang, 2016). In Shanghai, AlaHB ${ }^{6}$ started in 2010 as a community-based recycling platform supported by a state-owned recycling company (Tong and Tao, 2016). Green Earth, ${ }^{7}$ a community-based garbage sorting company in Chengdu, Sichuan Province, set up an information system for residential communities. With the slogan 'Trash is Cash', Green Earth provides incentives to registered members according to their performance in garbage sorting by tracking their discarding behaviour with RFID codes on the garbage bags they hand 
in (Tong and Tao, 2016). ${ }^{8}$ In Beijing, one of the best-known $\mathrm{O}_{2} \mathrm{O}$ companies is the Beijing Incom (Yingchuang) Resources Recovery Recycling Co. Ltd., which has developed a smartphone app named Bangdaojia. Its high domestic and foreign visibility is the result of sophisticated publicity policies. Taoqibao (developed by Beijing Zailai Keji Youxian gongsi) and Zai Shenghuo (developed by Anewliving), amongst others, are competing with Incom. At the time of writing (Spring 2018), the websites of these latter two companies were no longer active. Despite the rise and fall of some companies, the business model remains favoured. The Green Cat (Lümao) app was launched in Dongcheng District in April 2017 with the support of the Beijing Municipal Commission of City Management, which reposted the news on its website (Liu, 2017). Green Cat initially plans to service 20,00o households in the district, but over time and depending on the success of negotiations with the various departments involved, aims to expand that number tenfold.

All of these companies operate apps that are comparable to GEM's Huishouge, but some of them have looked for other ways to tap into the potential of this online-to-offline market and expand their operations (Illustration 2.1).Zai Shenghuo in particular has ventured into new fields that may serve as an example for others - and in fact some of them have already followed suit. Styling itself 'China's leading community life service platform', Zai Shenghuo has moved beyond collecting scrap and recycling activities. The company, originally established in Beijing in 2014 and expanding its operations to Shanghai in 2015, has added cleaning, odd jobs (extractor hood cleaning, knife sharpening, smartphone repairs, installing WiFi, etc.), and other maintenance services to its list of available activities. It also has a section for laundry services and offers the services of housekeepers, wet nurses, nannies, and nurses to care for the elderly. The first of these expanded services were announced with considerable fanfare around the 1 October festivities in 2016, and they now form such a large part of the company's activities that the original recycling work occupies a secondary position.

With garbage recycling becoming a billions-of-yuan activity, competition between these companies is fierce and becoming sharper all the time. Simultaneously, not all of the companies presenting slick apps and even slicker websites can stand close scrutiny. During Spring 2017, rumours made the rounds that the Taoqibao company had turned unresponsive. The app no longer worked and the general-service 400 phone number the company used for communicating with customers was not answered. The reason(s) Taoqibao

8 Radio-frequency identification (RFID) uses electromagnetic fields to automatically identify and track tags attached to objects. 
Illustration 2.1 Screenshots by the author of the Bangdaojia (left, Incom) and Zaishenghuo (right, Anewliving) apps showing some of their services. May 2018

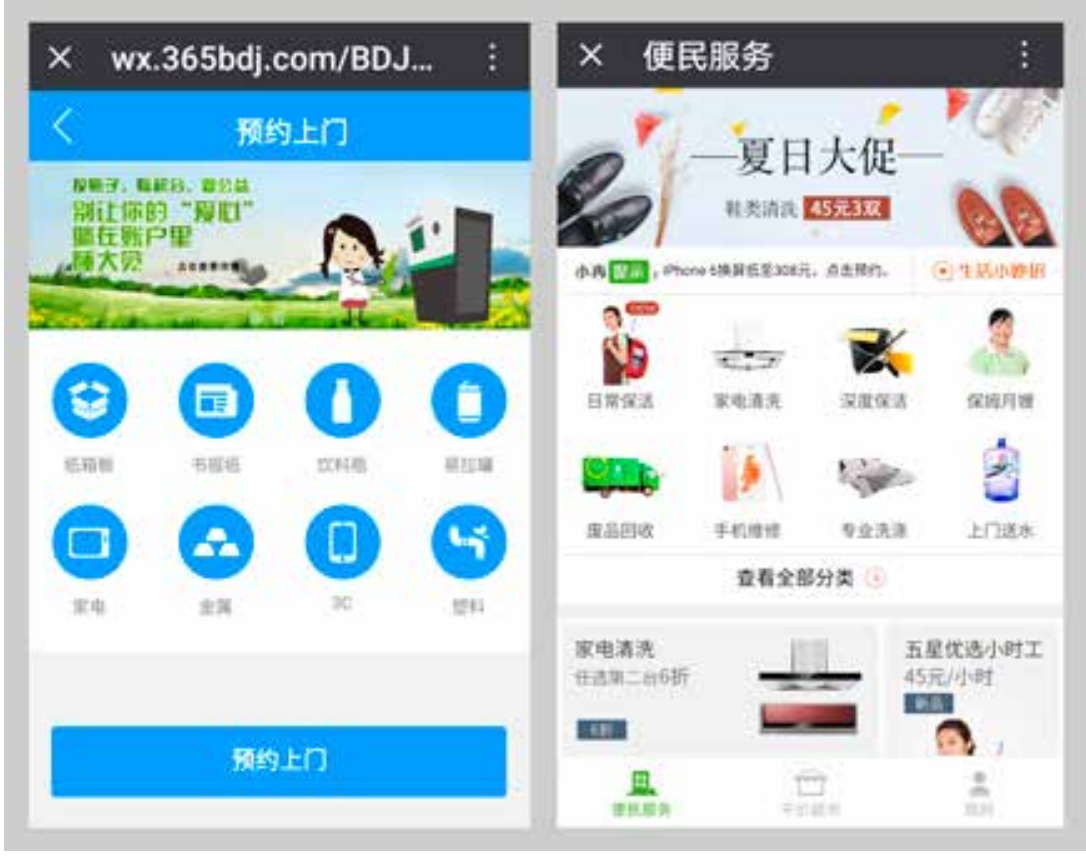

seemed to have disappeared remained unclear. More and more frequently, information circulated that Taoqibao's board of directors had vanished, taking the investors' money with them; according to people familiar with Beijing business practices, this has happened often (Interviews, 2017). A year later, in 2018, the Taoqibao website has ceased operations and been taken over by a company called Men's Heaven (男人天堂); the site is unresponsive.

All the companies mentioned here combine internet-related functions with activities in the physical world. Yet many questions regarding their operations remain. How successful are they, or have they been? Do the services they offer address consumer needs? How effectively have they harnessed the Internet? For some, waste collecting is no longer their main focus, but do those that continue specialize in specific types of garbage? And where does the waste go to, i.e., is the garbage recycled, incinerated, or landfilled, or all of the above? Have they merely become middlemen in a new, modern guise? Do the companies have an environmental consciousness and do they cooperate with environmental organizations, or are only looking for a profit (or dividends for their investors)? 


\section{Case study of Beijing Incom Resources Recovery Recycling}

One of the first Chinese companies that made use of big data in relation to recycling and the environment was the Beijing Incom (Yingchuang) Resources Recovery Recycling Co. Ltd. Set up in 2008, it boasts of offering a 'Total Solution for Intelligent Solid Waste Recovery Machine and Recycling System' (Beijing Incom Resources Recovery Recycling Co, N.d.). As part of the INCOM Resources Recovery Co., Ltd., which is in essence a regenerated bottle-grade PET chip manufacturer, the company's aim is to set up an overall recycling system with a stress on intelligent solid waste recovery and recycling. As far as obtaining the raw materials for recovery, Incom has developed reverse vending machines (RVMs) for the Chinese market that have until present focused only on retrieving plastic beverage bottles. On the outside, these RVMs look similar to the machines in many supermarkets in Western nations for returning glass or PET bottles that carry a deposit. One important difference with Western practices is the refund procedure. After all, PET bottles in general are produced for singular use and are intended to be thrown away, not returned. At the same time, in Chinese popular thinking, all trash has value, even when it can no longer be used (Minter, 2013a, 2013b, 2015). To entice people to leave their valuable trash in the machines operated by Incom, an incentive is offered: disposing of a plastic bottle will earn the recycler credit on his or her public transport card, or extra mobile phone minutes. The Incom RVM is able to 'buy back' PET bottles in three sizes (0.5 litre and smaller sizes; 0.5-1.2 litre; 1.2 litre and larger sizes), paying the recycler an amount of 5,10 and 15 fen Renminbi respectively, the equivalent of one half to 2 Eurocents (January 2017 rates). One can also refuse payment and simply donate one's recyclables (Su, 2014).

To operate RVMs in an urban Chinese environment, often outdoors, the machines had to be redesigned to meet specific requirements. To this end, Incom received financial support from the National Development and Reform Commission under the State Council to develop the machines currently operating (Kanthor, 2015). Incom rolled out its first RVMs for PET bottles in selected subway stations along Beijing's No. 10 subway line in 2012 (Zhang and Wen, 2014). The pilot project aimed to have 3000 RVMs in operation in the city, not only in subway stations, but also near or in schools, residential areas, bus stops, and shopping malls (Illustration 2.2). Once the trial phase had ended successfully, the company planned to have 10,000 units working in Beijing and 14 other large cities, including Shanghai and Shenzhen in 2016. 
Illustration 2.2 Two RVMs operated by the Beijing Incom (Yingchuang) Resources Recovery Recycling Co. Ltd, at the Panjiayuan No. 10 Subway Station

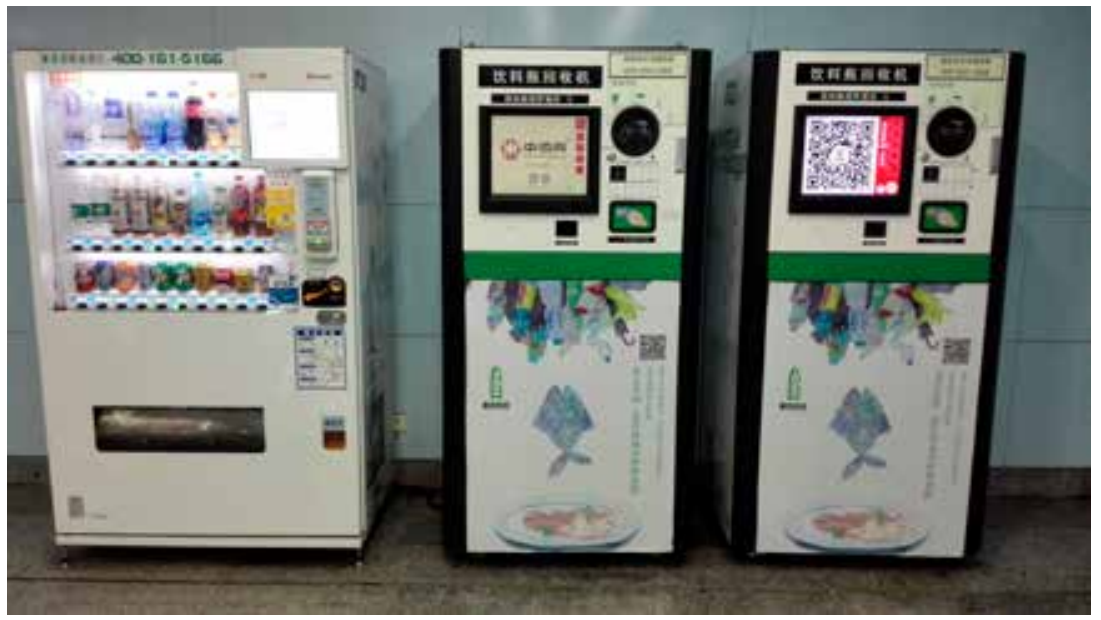

Author's photograph, 9 April 2017

The RVMs used for PET collection are integrated with machine-to-machine (M2M) communication technology. Once an RVM unit is full, it sends a message to the company's depot in Beijing's Shunyi district, whereupon a truck is dispatched to empty it. Its contents are then sorted and recycled in governmentapproved facilities and remade into new PET bottles (Kanthor, 2015). On the basis of fieldwork observations, I have established that this retrieving does not take place as often as the company maintains; for consecutive days, many of the RVMs that can be found on the company's website map were completely full without being emptied (marked in red) (Fieldnotes, 2017). ${ }^{9}$ The big data that are collected through the $\mathrm{M}_{2} \mathrm{M}$-process make the system attractive to the big brands producing beverages as well as to the government. The machines collect information from scanning the bar codes on the bottles and can provide a picture of current trends in consumption and recycling. Until now, Incom has supplied these data free-of-charge to the government and the brands that buy advertising space on the surfaces of the RVMs. Given the expertise it has gained in the process, the company has become one of the largest manufacturers and exporters of solid waste RVMs in China, but is also finding customers for its machines in Mexico, the Netherlands, Brazil, Thailand, and elsewhere.

9 A map of Incom's RVM locations in Beijing can be found here: http://www.incomportal. com/baidu/baidu.jsp. 
One of the main problems encountered by Incom has been the fact that the supply of raw waste materials, i.e., used PET bottles, for recycling is fluctuating, and that the net yield per RVM cannot be predicted. One can safely assume that beverage consumption is higher in periods of warm weather than in colder times, but aside from seasonal influences it is impossible to estimate the number of bottles that will be returned. Practice has shown that the amount of recyclable PET obtained from the RVMs remains far behind projected yields. Consequently, the recycling facilities that Incom has imported and installed cannot run at their full capacity. According to Incom, the reason is that the competition between RVMs and individual scrap collectors, the people roaming the streets, is too fierce. Or, to put it differently, it is more convenient for consumers disposing of empty PET bottles to dump them wherever and whenever they feel like it, in a waste bin or simply on the street, instead of making a conscious effort to go find an $\mathrm{RVM}$. Other $\mathrm{O}_{2} \mathrm{O}$ recycling platforms encounter similar problems in obtaining recyclables (Guo, 2016).

To alleviate this problem of contestation over access to recyclables, Incom has taken the opportunities offered by the government's Internet Plus policies a step further by developing an online-to-offline strategy to supplement the supply and demand of recyclable materials. Incom has added the smartphones of individual consumers or residential communities as a link in this chain. In May 2015, the company launched a smartphone application called Bangdaojia ('Help at Home') that can be installed and used by the consumer; the app runs on a host of mobile platforms, i.e., as a stand-alone app on Apple or Android, or integrated into Tencent's Weixin/Wechat. By 2017, the service covered 400 communities in Beijing (Zheng, 2017). Incom is not the first company to develop an app, but judging by the frequent media write-ups, it is certainly one of the most successful in drawing the attention of both Chinese and foreign media (PressTV Reporter's File, 2014; Kanthor, 2015; Zhang, 2016). This has made the solution adopted by Incom into a national (and potentially global) model for others to follow.

The Bangdaojia app can be downloaded by clicking the relevant link on the Incom website, ${ }^{10}$ which transports the consumer to the app page, and scanning the QR-code placed there. ${ }^{11}$ Once downloaded on a smartphone and registered by using the consumer's mobile phone number, anybody who has waste paper, plastic bottles, or other waste materials waiting to be picked up can report it in the app; at the same time, the app calculates how 
much the scrap offered for sale is worth. This option is not only available to individual consumers; the Bangdaojia website makes clear that the app can be used for/by residential communities, schools, and other (commercial) entities, ranging from offices to restaurants and shops. After indicating that scrap can be picked up, one of the 300 waste collectors employed by the company contacts the person that is offering the scrap, picks it up, and then transfers the money through a wallet app (Zheng, 2017). It remains unclear how Incom has hired the waste collectors, and how their contracts are structured. On their page of job offerings, analysed in Chapter 4, there are no vacancies for waste collectors listed.

Bangdaojia also gives access to a map that tells the consumer where the nearest RVM for PET bottles is located. By summer 2017, the app saw the addition of tabs for locations for the disposal of broken-down smartphones and used clothing, further proof that Incom is expanding its activities. By that time, the rejected smartphone market had already been well established and divided. The textile drop-off points was rather small in number and widely scattered, which does not bode well for the initiative. Moreover, the market for reused and recycled clothing in China is inefficient and riddled with scandals and corruption (Ma, 2017). However, all these steps contribute to the start of a recycling retrieval model that includes all types of scrap that are on offer.

\section{Effectiveness of the $\mathrm{O}_{2} \mathrm{O}$ model}

It is hard to say whether these companies have been successful with their recyclable retrieval activities and/or maintenance jobs, or whether they will continue to be so once the novelty of their operations has worn off. One of the main problems they encounter is the question of scale. In 2017, their services were not offered on a city-wide basis but were instead concentrated in the Eastern districts, i.e., Dongcheng and Chaoyang. Some had a few small bases of operations in the Xicheng and Fengtai districts, but these did not contribute to the bulk of their activities. The RVMs operated by Incom are the only ones that can claim citywide coverage. They are distributed fairly evenly over the breadth of the city, reaching out into even the suburban districts of Shijingshan, Changping, and Huairou; however, they are not encountered in subway stations as often as the company wants us to believe. Zhang and Wen (2014: 997) established in their research that their respondents were quite taken with the idea of the RVMs that Incom operates and were convinced that they would be useful for the collection of recyclable bottles. 
Illustration 2.3 A van operated by Taoqibao, at a Qianbajia waste collection point, formerly part of Henan Village, Haidian District, Beijing

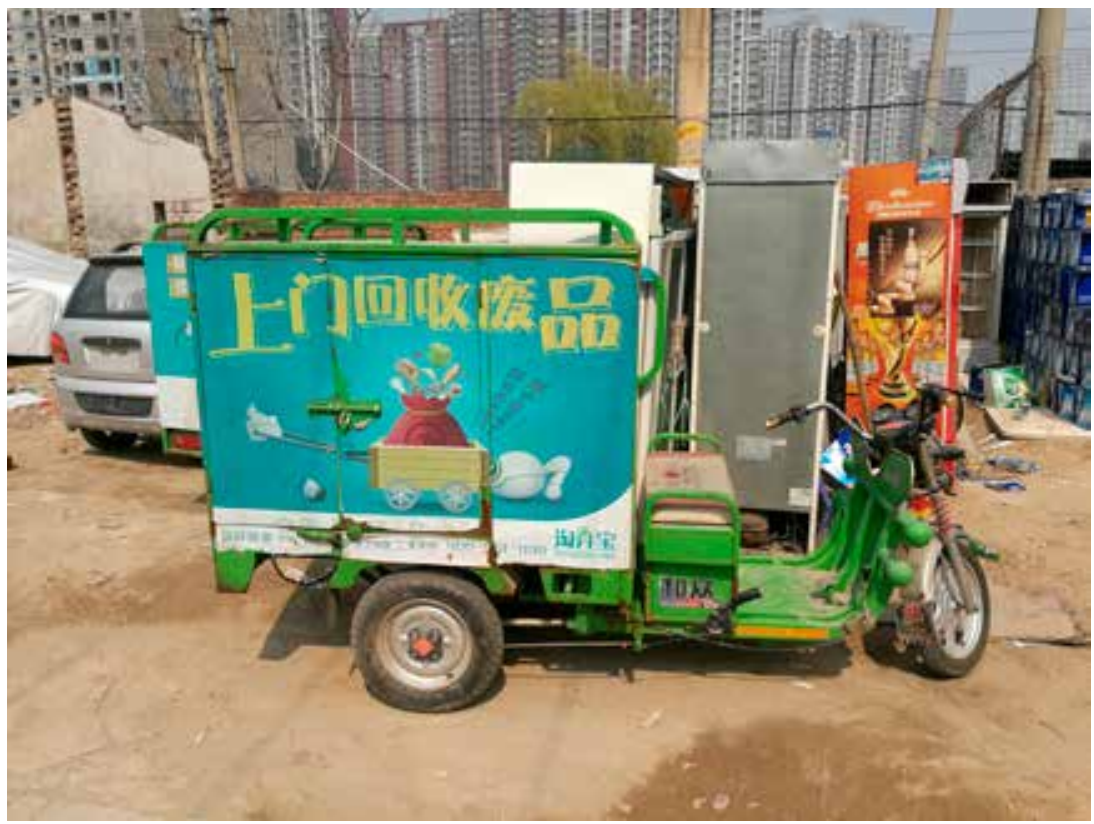

Author's photograph, 29 March 2017

Despite the amount of publicity given to their presence and write-ups about $\mathrm{O}_{2} \mathrm{O}$ activities in the (local and foreign language) media, and despite the various tools and machines that are conspicuously shown in these narratives, I did not spot a single $\mathrm{O}_{2} \mathrm{O}$-company retrieval truck during the three months of spring 2017. I only saw two vanlets operated by Taoqibao at one single garbage collection point in the Qianbajia area in Haidian district, the original Henan Village (Illustration 2.3). This part of town is actually not serviced by Taoqibao at all, as the company operated out of offices in Xicheng. Moreover, these vans gave a rather suspicious impression. Although they sported the Taoqibao logo and colours and carried the slogans the company used, they had obviously been painted over recently and had previously served as delivery vans for another company. This made both me and a number of bystanders wonder whether these vanlets were actually operated by Taoqibao, or if they had been shanzhai-ed, i.e., copied by others attempting to operate under the guise of the Taoqibao company for their own purposes. If it was worthwhile to copy the practices of Taoqibao, it must mean that the company was hugely successful. As there are questions surrounding 
Taoqibao's success, it seems that some (informal?) waste pickers may have thought that having recognizable company colours would improve their income. The remarks and opinions of waste collectors and collection point bosses that I recorded and that I present in Chapter 4 suggest otherwise.

As my interviews showed, not many of the intended users were actually familiar with the services the $\mathrm{O}_{2} \mathrm{O}$-companies offered. Most people had never heard of them; others, without actually knowing anything about them or their business models, immediately characterized them as only being interested in valuable waste, in particular e-waste. Various respondents acknowledged that their services could be convenient but reckoned that they were not really needed. They were elated that the set prices for recyclables in the applications meant that waste pickers would no longer be able to cheat. And they hoped that the applications would bring more order to the waste-collecting business, meaning that their communal waste bins would no longer be ransacked by informal scavengers, with the waste strewn about carelessly. However, none of these considerations made them contemplate joining an $\mathrm{O}_{2} \mathrm{O}$ scheme. 